\title{
WHERE THEY ORIGINATED... SOME CONTEMPORARY LEGENDS AND THEIR LITERARY ORIGINS
}

\author{
Rolf W. Brednich
}

I started collecting contemporary legends in Germany in the early 1980s and published my first collection in 1990 which was followed by three other volumes in 1991-1996 with a total of ca. 500 text types published. Hence though I did not have the ambition to compete with "Mister urban legend", Professor Jan H. Brunvand of the USA and his famous editions "The Vanishing Hitchhiker" or "The Mexican Pet", my collections have been very well accepted by the German speaking reading public. More than one million copies have been sold to date, and three of my four paperbacks have been translated into a number of European languages and into Japanese. This indicates that contemporary legends are easily transferable from one language and culture to the other. On their way across the borders they need only some additional local or regional motifs or narrative details to be attractive again.

Speaking in general terms, contemporary legends are no longer the characteristics of the narrative culture of a nation, but they belong to a new strata of oral tradition with a world wide distribution. This is due to the increased mobility of our modern society, to tourism, and of course to unlimited international communication and networks. Through these channels the stories about strange and curious events and mishaps are easily transmitted from continent to continent and become again a part of oral circulation and dissemination. Contemporary legends can be regarded as an indication of a world-wide society living in a global village which, at least partly, shares the same wishes, longings, values and anxieties. Although their actual circulation and distribution is heavily supported by the modern mass media, contemporary legends basically belong to oral tradition, and they prove by their existence that even in our modern technical world hundreds and hundreds of stories are still generated and transmitted from mouth to mouth.

http://www.folklore.ee/folklore/vol20/legends.pdf 


\section{Rolf W. Brednich}

The scholarly investigation of the genre started with the first Sheffield conferences in the early 80 s and currently lies in the hands of a group of specialists centred around the International Society for Contemporary Legends Research (ISCLR). It publishes the Foaftale Newsletter and the Yearbook "Contemporary Legend" and its members meet every year in Sheffield or other places. Unfortunately, the scholarly contributions to these conferences are no longer available in print as were the former proceedings, edited by Paul Smith and Gillian Bennett.

In the decade since the white heat of the initial projects faded, much has changed. Although contemporary legends (or urban myths) are, beside jokes and ethnic slurs, still the most lively and powerful genre of modern folklore, we now have to relate to an increasingly efficient system for recording and disseminating knowledge. As the body of information increases, so does its periphery, and the grey areas beyond its margins begin to take on a life on their own. This effect was evident from the earliest days of the Internet: one of the first discussion groups to emerge from the techno-programming chat was a forum dedicated to urban legends (Alt.folklore.urban, which still exists as the powerful AFU \& Urban Legends Archive on the Net). After the discovery of the new genre itself and its hundreds of attractive topics, the interest soon shifted towards the question of their truth. "Did that really happen or not?" "Does the Vanishing Hitchhiker exist or not?" "Was there ever a killer in the back seat arrested and where?" "Is there any evidence that sperm in a bathtub can cause pregnancy?" "Do Antarctic penguins really fall over onto their backs whenever jets happen to fly over their colonies on the beaches of the Falkland Islands?" Or even less likely: "Is it true that a penny dropped from the Empire State Building would make a deep dent in the pavement or even could kill a person?"

The attempt to classify these and thousands of other questions produced a bewildering number of ontological categories: "Tb" for "believed true but not proven", "Ft" for "mostly untrue but with a true occurrence or known origin", "U" for "unanswered and/or unanswerable", "P" for "may not have happened but theoretically possible", etc. Even the titles of the urban legends newsgroups reveal that what was once the domain of professional folklore collectors has now turned into a mass entertainment situated between game 
and gossip: www.snopes, www.redrival, www.scambusters, www.netsquirrel, www.toybox. The snope-newsgroup for example is the voice of a "San Fernando Valley Folklore Society" - in other words some folklorists themselves have started to produce the material which a future generation may be eager to collect. Other newsgroups such as www.hoaxkill.com have started warning their users against trusting rumours or believing in mere hearsays. www.netsquirrel provides you with the ultimate "Urban Legend Combat Kit" and caution against forwarding email hoaxes to your friends that promise that "something great will happen" if you send an email to all yours friends (M\&M is going to give you a free case of M\&Ms if you do that).

The impetus from global communications has given contemporary legends a high degree of potency in the real world. The most unlikely yarns have been picked up by press agencies and TV stations. Ulrich Wickert, a well known German TV news speaker used to end his late night news show for a long time with an abbreviated version of an urban legend taken from the Internet. So the Net itself has become the prime breeding-ground for new generation of urban, sometimes even dangerous, legends. Reuters and Proctor \& Gamble have been forced to change their corporate logos as a result of persistent rumours about their Satanic symbolism. Marlborough had to do the same with its cigarette boxes because of suspicion of affiliation with the Ku-Klux-Klan, and the German producer of the famous Birkenstock sandals had to defend himself publicly through newspaper advertisements against reproaches that his money supported neo-Nazis.

Furthermore, the publication of seemingly endless collections of texts for the use of the common reader has shifted from the hands of folklorists to those of journalists and collectors/editors with no interest in scholarly research, only in providing material for dinner-party anecdotes. They want to entertain, frighten or amuse their readers with the most ugly, nasty and sensational narratives. Films like "Urban Legends" or the "Blair Witch Project" have contributed to public acknowledgement of modern legends as a separate genre and as a an integral part of contemporary society.

Given such a situation, I strongly urge a re-engagement of folk narrative researchers with this field. I regard it as our duty to regu- 


\section{Rolf W. Brednich}

larly inform the public about the results of scholarly research, which should not be concealed in our journals, newsletters and yearbooks. We should not leave the entire field, which we once initiated, in the hands of what Richard Dorson once called fakelorists.

My present paper aims to examine the origins of some of these international narratives and the meanings they transmit. The most important source of contemporary legends is life itself, i.e. a considerably high percentage of the texts go back to real events: a "grain of truth" (German: ein Körnchen Wahrheit) is preserved in these stories. The truth is often concealed behind the imagination of the storytellers who, by changing details or adding new motifs, make the stories a part of their own world view. Those elements of the texts which seem to be invented or constructed, however, should not be called "untrue" or false. They are still realistic and could have happened as reported. And you never know if they will happen in the future in the same or similar way as they have been reported.

Our responsibility as researchers is not so much to prove the truth and to answer the question as to whether they ever happened, but to inquire into the basic meanings of contemporary legends. If we start asking about the cultural significance and values transmitted by them, this will open up, at least in theory, a world without limits. The reluctance of scholars of urban legends to delve into this field is understandable, because it would no longer provide topic for dinner-parties. But it would lead to deep insights into our attitudes, prejudices and suppressed wishes. In this respect, not much has been done to date. To give just one good example: Bent af Klintberg was the one to ask the question "Why are there so many legends of revenge?" And his answer was that deep inside us there is a suppressed wish to take justice in our own hand and to do what the law prohibits us from doing. Instead of doing so we narrate urban legends about revenge: Sounds plausible, but it does not make you popular. The same would be the case if you would do in-depth studies about the widespread xenophobia which persists in these legends, which tell you that foreigners want to steal your kidneys, your cars or even your children, and that it is even more dangerous to travel into the homelands of these strange and frightening beings. 
Of no less importance is the often intriguing search for the sources of contemporary legends. In particular the role of literature in the process of transmitting narratives and the changing meaning of the plots deserves further investigation and scholarship. This gives me the opportunity to come to the focus of my paper. A certain portion of modern legends are literary inventions which can be traced back to known authors. The British writer Roald Dahl e.g. had the talent to create many a short story which in their structure resemble contemporary legends. Some of them like "Chippendale", "Lambleg" or "The Red Wine Conoisseur" entered into oral circulation. The search for literary elements in modern folklore is a relatively new approach in folkloristics. Most past studies worked the other way round. It was very common to look for folklore elements in the work of prominent authors. "Folk in Lit" studies have been very popular in the US. Looking for literary sources in modern oral folklore is not less challenging, and promises some unexpected results concerning the relationship between orality and scriptuality, a debate which is always going on in our discipline. Let me give you a first example.

In my third collection of contemporary legends I have published the following text (slightly shortened):

The brother-in-law of a fellow student of my informant has told him, that on a flight from Madrid (Spain) to Munich (Germany) he met a German couple who experienced an almost unbelievable adventure during their holidays in Spain. They visited a church in Madrid and did not pay attention to the time. They got locked in and had to spent the night in the church. After the bell had rung midnight, the organ suddenly started playing and from a side portal a procession of disguised monks holding burning candles moved to the altar, escorting a girl with a shaven head dressed in a shirt. At the altar, the monks removed a big tile from the floor, to give access to a dark dungeon. After a hymn was sung and a prayer murmured, the girl was pushed into the abyss and the tile set back in its old place. With the play of the organ, the strange monks' procession headed for the hidden door and disappeared. This was all observed by the German couple from the shadows in the background and they were stiff with terror. As soon as they could get out of the church next morning, they im- 


\section{Rolf W. Brednich}

mediately went to the German consulate to record their experience. They were strongly recommended to keep their secret to themselves, and to leave the country as soon as possible. So they did, and not before the aircraft entered into German territory did they dare to speak about their adventure to their neighbouring passenger.

The story has everything that makes a good contemporary legend:

It is topical (it is reported to have happened in 1990), it is exciting, plausible and credible, and it meets some common prejudices about conservative Spain and the enigmatic role of mysterious secret societies which act as the executive of the supposedly continuing inquisition. There is as female victim, probably an adulteress (her crime is not specified), there is a male court, there is the horrifying penalty of being buryed alive, which sounds medieval, there are witnesses: all this sounds logical, so it could be true... But is it true? Has my informant reported about a real event?

I don't think so: the story is too neatly plotted to be believed. My suspicion arose with the first variant, which I heard from a Polish colleague who told a slightly different story about a similar couple who left their hiding place after the mysterious procession had disappeared and looked behind the altar, where they found an open trunk with a skeleton inside. This is again oral folklore, but now we will go a step further, into booklore or literature. The German writer and dramatist Erwin Guido Kolbenheyer (1878-1962) heard a quite similar story from a friend of a friend (a photographer and architect), and included it - enriched by some dramatic effects - into one of his works that was intended to be evidence of the power of Catholicism under the fascist Franco regime in Spain in the 1930s.

But to discover the real literary background of the story we must go back to the early 19 th century. The preference of romantic literature for the sphere of the night, for monasteries and convents, for nocturnal processions and funerals, is well known, and will not be dealt with here in detail. It is sufficient to trace back the specific motif of the girl buried alive in Romantic literature. We find it in one of the outstanding pieces of "night literature" of this time, in the Night Watches of Bonaventura which appeared in a series of "New German Original Novels" in 1804. The anonymous work was 
for a long time attributed to the philosopher Friedrich Schelling, but later on other names like Friedrich Gottlob Wetzel ( $\dagger$ 1819) or Ernst August Klingemann have been brought into discussion of the probable authorship. For our purposes, it is more important to know that this novel, more or less a collection of short stories - composed and to a remarkable extent depending on fragments of stories already in circulation - became very popular in the 19th century, and that its 10th chapter contains the story we are interested in: It is entitled Dream of Love and - with obvious allusions to G. A. Bürger's Lenore - tells the story of the author's nocturnal visit to a convent of St. Ursula. The watchman invites him to be witness of a strange incident: "They're playing Let's Bury-It in the convent, the old man continued -, do you want to watch? A chaste Ursuline became a mother today; - in legend it would, of course, be recorded as a miracle; however, they have peeked so often at God's cards that nowadays they no longer believe in any miracle. The saintly virgin will be buried alive this night. I'll let you in; take a look to pass the time!" [The romantic irony or even the sarcasm of the text cannot be overheard. Therefore, the witness is not very much horrified by what he sees from behind a pillar]: The nun is entombed into a dark vault with a jug of water, a loaf of bread, a crucifix, and a prayer book. The scenery including the nocturnal procession, the playing of the organ, the singing, etc. is very much the same as in our oral legend of 1990. At the end of the episode the child of the nun buried alive is entrusted to the nightly visitor who renders it to the desperate father of the child.

For Bonaventura, the burial alive of a sinful nun is a metaphor. Together with the other bizarre episodes of his novel, it stands for the author's radical anti-humanistic philosophy that the world is perverse and tragic and that people act in it as helpless puppets. Even convents, although they might be seen from the outside world as safeguards of cultural values, prove to be medieval and deeply inhuman. Contrary to the oral version, the literary document provides the motivation for the cruel punishment of the woman. Apart from this detail, we can conclude that there seems to be a continuity between the romantic tale of 1804 and the contemporary legend. Generally speaking, in fact, contemporary legends preserve bits and pieces of literary sources, especially the most memorable and tragic ones, which it is possible that could be true. In the work 


\section{Rolf W. Brednich}

of Kolbenheyer, the episode of the nun buried alive is still a literary metaphor, elucidating the power of Catholicism and inquisition in modern Spain. In the modern legends, the metaphor is eventually reduced to the mere fact that travelling in foreign countries might be dangerous or frightening. Nevertheless, the old concept of Hans Naumann's theory of "Gesunkenes Kulturgut" (sunken cultural values) could be still applied to the oral narrative. But in doing so, we no longer believe in the ideology that the "folk" telling such a story today is a full hundred years behind the achievements of socalled high or sophisticated culture. The process of interrelationship between written and oral literature can occur at any time and any place: it is not a matter of high and low literature or culture, it is just a question of communication and reception. Moreover, it is reversible, because at the same time orally circulating narratives can be transformed, as well, into literary short stories, novels, film episodes, TV series, radio programmes etc. Everything goes...

Let me give you another example of the same process. This time I will start with the literary source of a contemporary legend. In the late 1930s, the German authoress Sophie Droste-Hülshoff, a descendant of the renowned Westphalian Hülshoff family, wrote a short story entitled "The Revenge of the boys of Winkelhofen" (a funny story from Upper Bavaria). Content: Twice a year in Winkelhofen there is a country fair. To both of them a man ("Schausteller") would appear with a shooting gallery and a chair-o-plane [Kettenkarussell]. The Winkelhofen boys would be responsible for the functioning of the latter and as a reward they would get a free ride every sixth round. One year the man came up with an old engine which replaced the manpower of the boys. They took revenge by removing the brake-handle ("Abstellhebel") from the motor to the effect that the fair inspection committee, which was offered the first ride free, gets trapped in the chair-o-plane and has to ride between earth and sky for a long time until the forester of the village gets the idea of shooting the motor to pieces, which he finally does on his fourth shot.

Again there is the quest for Meaning, rather than for the truth. This little story can be regarded as a narrative metaphor for the arrival of modern technology in the Bavarian countryside, the boys being the representatives of the traditional way of life. When we 
turn to the world of contemporary narratives inspired by the literary model, the meaning of the story is quite different. I have collected several variants which can be summarised as follows:

After a birthday party, three friends decide to go to a country fair in a small village near Kassel in Hessen. But it is already midnight, and everything is turned off. They succeed in waking up the owner of the chair-o-plane. Being very friendly and talked into it by a bottle of wine, he turns his engine on and joins the three young men riding his chair-o-plane. But: there is nobody to stop the engine, all shouting is in vain, and they have to stay on for the whole night until they are released the next morning. The effect on the three students is disastrous: one is dead, the second became insane during the night, and the third one jumps off, survives, and decides to totally change his life.

If this can be called a (narrative) metaphor it stands for the dangers of modern technology, which has to be handled and supervised very carefully, or else it produces terrible effects on human life.

Almost the same moral is the focus of another contemporary legend of world wide distribution, based in Australia. It is entitled "The Run-Over", and one of my German versions tells the following:

A group of four South German tourists is travelling by rented car in the Australian bush when they suddenly run over a kangaroo. Being good Germans, they call in at the next farm and ask how to handle the damage they have done. The farmer laughs at the question and proposes that they take a picture of the animal. They head back to the fatal spot and put of the kangaroo in front of the car. One of the tourists takes his jacket and drapes it around the animal's shoulders. Before the photographs could be taken, the kangaroo came to life again and escapes into the bush, carrying with the jacket the passenger's passport, air ticket, driver's licence and credit cards.

The literary source of the story seems to be more than sixty years old. According to Amanda Bishop, its first evidence was in the work of the Australian author Ron Edwards "Yarns and Ballads of the Australian Bush". He tells the tall tale of a kangaroo that escaped with a sum of 200 Dollars [presumably 100 pounds in the old days] 


\section{Rolf W. Brednich}

in a pocket of a jacket and needed 15 years to spend the money on beer in a local pub. From the kangaroo country of Australia, the story has migrated to several National Parks in North America where the animal to disappear with the personal belongings (or even a baby) of a group of tourists is said to be a bear. In this case, I am not sure about Ron Edwards being the inventor of the story. He could just as well have heard it from an oral source and used it for his bush yarn. If so, it would give us an example of the long lived and never ending interrelationship between oral tradition and written literature. And again, the meaning of the story is different in literature and in folklore: Told as an Australian bush yarn, it is just a funny tall tale, and nobody would really believe it; told as a contemporary legend it can be regarded as a true story. After I published the story in my second collection of "legendary tales of today", I got a letter from a German business man who claimed that exactly the same thing happened to him in 1982 and he could even prove it by enclosing the telegram in which he asked his German boss to send him money and a provisional identification because an Australian kangaroo run off with all his articles of value.

In conclusion, if my proposal for considering the quest for origin and meaning in contemporary legend research (instead of for truth or untruth) were to be taken up, it would give us much to do in the future. It is a considerable challenge to investigate phenomena of our increasingly media-dominated world. It seems that however despite its technological trappings - an essentially oral culture will always survive. Contemporary legends may have literary origins or be a creation of our own times, but there will always be the homo narrans.

Paper presented at ISFNR Congress, in Melbourne, 2001 